\title{
Employability of Bachelor of Science (Agriculture) Graduates of Bangabandhu Sheikh Mujibur Rahman Agricultural University
}

\author{
Md. Safiul Islam Afrad*\& Aliyu Akilu Barau
}

Department of Agricultural Extension and Rural Development, Bangabandhu Sheikh Mujibur Rahman Agricultural University, Gazipur-1706, BANGLADESH

DOI: https://doi.org/10.30880/jtet.2019.11.02.007

Received $06^{\text {th }}$ November 2018; Accepted 31 ${ }^{\text {st }}$ March 2019; Available online $30^{\text {th }}$ June 2019

\begin{abstract}
Employability is a contemporary global concern of developing countries which indirectly affects other categories of countries. Hence, the necessity for institutions turning out graduates to focus on ensuring their products meet market demands. The present study was therefore, centred on employability of Bachelor of Science Agriculture graduates of BSMRAU. Mixed research methods were adopted to conduct a survey on 140 (Master of Science students, Alumni and Service providers) respondents concerning generic skills and job performance. Quantitative data were analysed using descriptive statistics such as mean, percent, frequency and range in SPSS software, while qualitative data was analysed through collection of themes with respect to the study objectives. Results revealed that majority of graduates dominantly acquired generic skills related to communication and ICT, interpersonal, teamwork and leadership skills, and self-management and personal development skills from Agricultural Extension and Rural Development offered courses. The employability trend of Bachelor of Science Agriculture graduates was obtained to be high in the early years after graduation and decreases afterwards. Governmental organisations that include research, extension, education and bank absorbed majority of the graduates. Higher level of satisfaction was expressed in teaching-learning, communications skills and process control, while curriculum update and knowledge achievement were low satisfied. Major perceived strength was adherence to academic calendar while less extracurricular activities was the major weakness. Carrying out practical in a practical way and provision of some important laboratory equipment were the key areas suggested for improvement.
\end{abstract}

Keywords: Agriculture, employability, graduates, skills, university

\section{Introduction}

Employability is a critical issue for both government and Higher Education Institutions (HEIs) (Saunders \& Zuzel, 2010). However, in the context of this study employability was defined in the view of York (2006) 'a set of achievements - skills, understandings and personal attributes - that make graduates more likely to gain employment and be successful in their chosen occupations, which benefits themselves, the workforce, the community and the economy'. Establishments usually expect graduates to have well developed employability skills, such that they can meet up with the needs and challenges in and associated with the place of work. In the opinion of Saunders and Zuzel (2010) the current trend of placing increased emphasis on graduate/key skills dictates that the higher education curriculum incorporates opportunities to develop such skills in conjunction with subject specific skills and knowledge. This equips graduates with the required knowledge and skills necessary to get along with the dynamic trends of the employment. Be that as it may, universities are expected to train students capable of gaining employment after graduation.

On the other hand, Bangabandhu Sheikh Mujibur Rahman Agricultural University (BSMRAU) launched its undergraduate program in 2005 to offer Bachelor of Science degree in Agriculture (BS Agriculture). The University is 
committed to the policy of providing educational opportunities to all eligible students regardless of their economic or social status, and does not discriminate on the basis of race, color, sex, creed, age, marital status or national origin. Therefore, academic excellence at all levels, is its vital concern, and is always ready to extend its cooperation to the students. So far, since 2009, there are 749 students who have graduated in eight batches from the faculty of agriculture, BSMRAU, Gazipur, Bangladesh.

After graduation, some of them secured their MS degree from this university and also from other universities within and outside Bangladesh. Many of the BS Agriculture graduates of BSMRAU have been engaged in rendering their services in different nation building in the various government and non-governmental organizations both home and abroad. But till today, there is no documentation about employability BS Agriculture graduates of BSMRAU. Besides, level of satisfaction on the academic achievements and suggestions for further improvement of BS Agriculture program were also not documented. For improving this BS Agriculture program, it is obvious to get feedback from different stakeholders. The present study results would on a larger scale provide a framework that can be employed in assessment of agriculture undergraduate program towards increasing employability and academic achievement, and reducing the likelihood of retrogression. The findings of the research could be used by education policy makers, university management, university regulatory agencies, academics, and government for improving overall effectiveness of the university system. Similarly, the findings provide a research evidence based framework that could guide practices aimed at meeting the needs of all students and other stakeholders, especially the employers of labour. In view of the above circumstance, the present study was embarked upon to achieve the following objectives:

$\checkmark$ To assess the graduate profile/generic skill of BS Agriculture graduates of BSMRAU;

$\checkmark$ To evaluate the employability of BS Agriculture graduates of BSMRAU in different organisations; and

$\checkmark \quad$ To explore the levels of satisfaction on academic achievements and suggestions for further improvement of BS Agriculture program.

An extensive study of the University Grants Commission, Bangladesh (2016) self-assessment manual and Kirkpatrick 4-level evaluation model for educational program (Kirkpatrick and Kirkpatrick, 2006) guided the researchers in synthesizing the following conceptual framework to represent the interrelationship of key variables as well as actions required to attain the goal of the degree program. The conceptual framework is thus presented as follows:

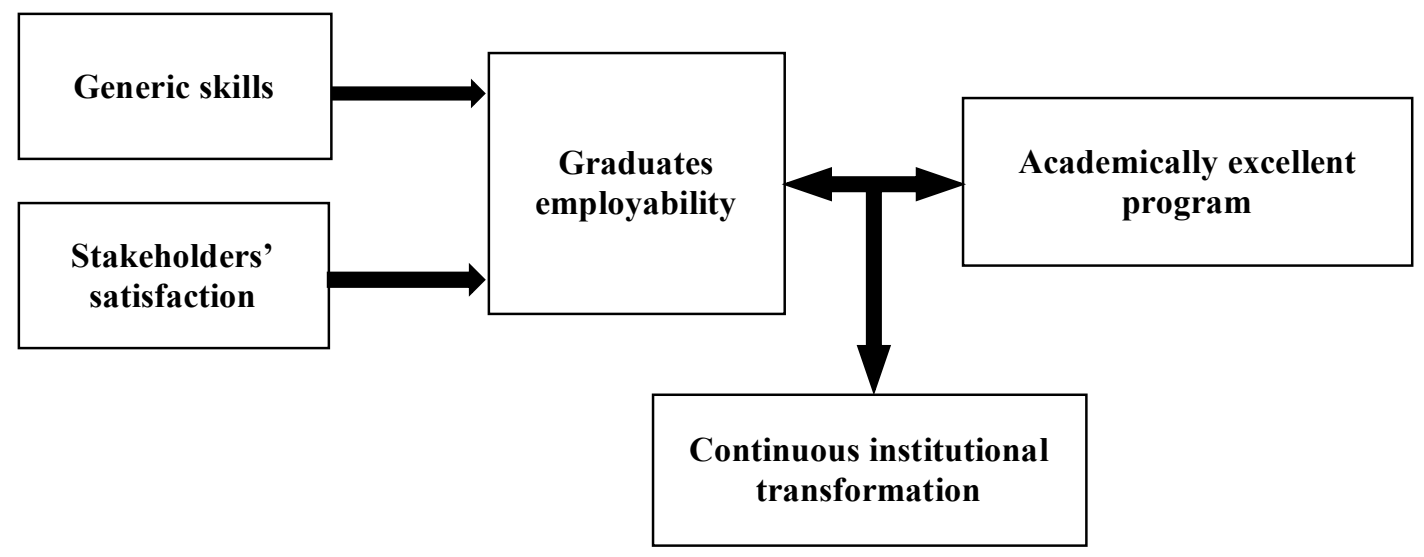

Figure 1 - Conceptual framework of the study

The ultimate goal of studying employability of BS Agriculture graduates of BSMRAU was to establish a fundamental basis upon which sustainability of academic excellence could be achieved, by way of guiding students through effective and time demanding teaching-learning process to develop cutting edge generic skills that would satisfy them and other stakeholders, thus, employability. But, to maintain employability of graduates there must be continuous institutional transformation in academic and non-academic affairs that would ultimately lead to academically excellent study program and vice-versa.

\section{Methodology}

Mixed methods research design was adopted in this study. As such, both quantitative and qualitative data were employed. These included collection of quantitative data from 20 alumni, 20 service providers and 100 MS degree students who completed their BS Agriculture from BSMRAU using interview schedule, and focus group discussions (FGD) for the qualitative data. The sampling technique used was proportionate stratified random sampling. The sample from each stratum in this sampling technique is proportionate to the population size of the stratum. That is, selection of sample from each stratum (alumni, service providers and MS degree students who completed their BS 
Agriculture) was proportionate to its population size. To measure the generic skills of the graduates, viz. cognitive skills, practical \& problem solving skills, numeracy and analytical skills, entrepreneurship and innovation skills, communication and ICT skills, interpersonal, teamwork \& leadership skill, self-management \& personal development skills and commitment to community, country and humanity UGC (2016) was followed. For evaluating the job performance of the graduates, six parameters viz. competency, productivity, communication skills, commitment cooperation and professionalism were considered following Burkart (2013). For both of the two major variables, a 5point Likert-type scale that ranged from "strongly agree", "agree", "no opinion" "disagree" and "strongly disagree" was used to collect opinion of the respondents and scores of '5', '4', ' 3 ', '2' and ' 1 ' were assigned against each of the responses, respectively.

After field survey, quantitative data were analysed by using descriptive statistics, viz. frequency, percent, mean, range and standard deviation (SD). Mean values of the responses made by the different stakeholders were computed which showed their average opinions regarding the graduate profile/generic skill of the graduates, level of satisfaction on their academic achievements and job performance as perceived by their service providers. As for the qualitative data, suggestion of Miles and Huberman (1994) for qualitative data analysis was adopted. It encompasses three simultaneous actions: data reduction; data display; and conclusion drawing/verification.

\section{Results and discussion}

Major findings and their logical discussions have been presented in this section based on the objectives of the study.

\subsection{Graduate profile/Generic skills}

Skill which is the ability to perform a learnt act, enhances worth, competence and potential of an individual. Results shown in Table 1 indicate the perception of the students on skills acquired by them was measured based on eight generic skills with respect to the various departments that offer courses for BS Agriculture. In terms of cognitive skills, genetics and plant breeding, and soil science had equal highest score (3.63). Soil science and statistics also had equal highest score (3.46) in terms of practical and problem solving skills. Agricultural economics and, genetics and plant breeding had nearly equal highest score (3.56 and 3.54, respectively) in numeracy and analytical skills. Agricultural extension and rural development had highest scores in entrepreneurship and innovative skills (3.26), communication and ICT skills (3.88), interpersonal, teamwork and leadership skills (4.18), and, self-management and personal development skills (4.04). Genetic and plant breeding had highest score (3.00) in terms of commitment to community, country and humanity.

On the overall perception of BS Agriculture students' generic skills, agricultural extension and rural development was highest in both number of skills and value of scores. It is followed in decreasing order by genetics and plant breeding, soil science, agricultural economics and statistics, respectively. On the other hand, animal science, agricultural engineering and fisheries had low scores. Therefore, finding indicates the need for more generic skills development for better performance of BSMRAU BS Agriculture graduates. Although, Smith and Bath (2006) reported that the social, interactive and collaborative characteristics of students' university life experiences are important determinants of generic graduate outcomes, the present findings demonstrated that the connectivity of learners with real life experiences outside the university walls through field trips, exploring field situations of farmers to establish links with theoretical knowledge learned during class works as well as debating over issues of practical relevance in professional or occupational career which were all obtained from agricultural extension and rural development courses take the centre stage in developing generic skills of BS Agriculture graduates.

\subsection{Employability}

The 8 batches BS Agriculture graduates produced by BSMRAU so far, have considerably got absorbed out of the labour market. Figure 1 shows that with increasing years after graduation the rate of graduates employment decreased between 2009 and 2016 ( $1^{\text {st }}$ to $8^{\text {th }}$ batch, respectively). Fresh graduates were absorbed faster in large numbers thereby leaving behind a few in the labour market which made the unemployed consitute a small percentage with increasing years after graduation. 
Table 1 - Opinion of the respondents on perceived generic skills of BS (Agriculture) graduates of BSMRAU

\begin{tabular}{|c|c|c|c|c|c|c|c|c|c|c|}
\hline SI\# & Name of Department & & 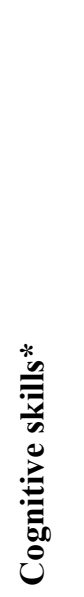 & 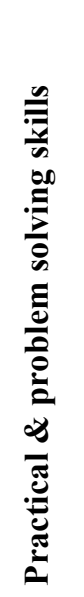 & 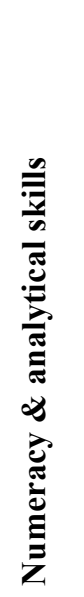 & 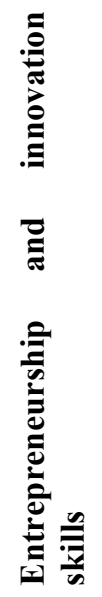 & 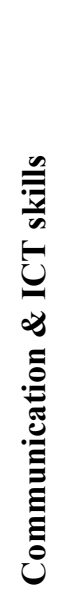 & 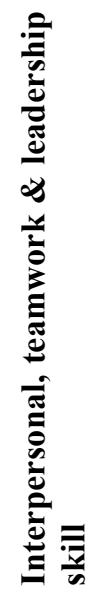 & 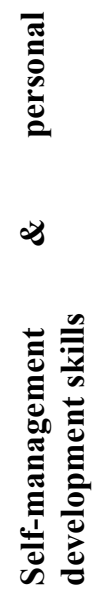 & 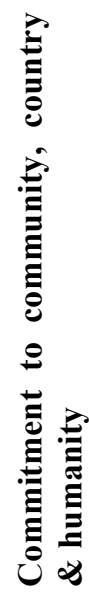 \\
\hline 1. & Agricultural Economics & & 3.19 & 2.40 & 3.56 & 1.74 & 2.11 & 2.58 & 3.25 & 2.96 \\
\hline 2. & $\begin{array}{l}\text { Agricultural Extension and } \\
\text { Development }\end{array}$ & Rural & 3.51 & 3.28 & 2.67 & 3.26 & 3.88 & 4.18 & 4.04 & 2.70 \\
\hline 3. & Agroforestry and Environment & & 3.04 & 2.40 & 2.32 & 2.16 & 1.91 & 2.39 & 2.65 & 2.63 \\
\hline 4. & Agricultural Engineering & & 2.47 & 2.84 & 2.63 & 2.14 & 1.84 & 2.11 & 2.14 & 2.07 \\
\hline 5. & Statistics & & 2.93 & 3.46 & 3.39 & 2.49 & 2.82 & 2.47 & 2.67 & 2.23 \\
\hline 6. & Agronomy & & 3.37 & 3.33 & 2.96 & 2.40 & 2.19 & 2.70 & 2.61 & 2.79 \\
\hline 7. & Animal Science & & 2.84 & 2.26 & 1.95 & 2.28 & 2.00 & 2.12 & 2.12 & 2.21 \\
\hline 8. & Biochemistry & & 3.18 & 2.70 & 2.67 & 2.16 & 1.98 & 2.19 & 2.35 & 2.30 \\
\hline 9. & Biotechnology & & 3.58 & 3.09 & 3.02 & 3.12 & 2.46 & 2.77 & 2.61 & 2.82 \\
\hline 10. & Computer Science & & 3.14 & 3.42 & 3.51 & 2.93 & 3.44 & 2.70 & 2.68 & 2.67 \\
\hline 11. & Crop Botany & & 3.37 & 3.05 & 2.96 & 2.42 & 2.18 & 2.44 & 2.60 & 2.40 \\
\hline 12. & Entomology & & 3.53 & 3.07 & 2.58 & 2.42 & 2.21 & 2.79 & 2.63 & 2.63 \\
\hline 13. & Genetics and Plant Breeding & & 3.63 & 3.70 & 3.54 & 3.14 & 2.49 & 2.51 & 2.70 & 3.00 \\
\hline 14. & Horticulture & & 3.11 & 2.61 & 2.44 & 2.40 & 1.86 & 2.35 & 2.39 & 2.18 \\
\hline 15. & Introduction of Fish Culture & & 2.28 & 1.84 & 1.75 & 1.70 & 1.63 & 1.89 & 1.88 & 1.91 \\
\hline 16. & Plant Pathology & & 3.44 & 3.28 & 2.77 & 2.75 & 2.14 & 2.58 & 2.82 & 2.82 \\
\hline 17. & Soil Science & & 3.63 & 3.46 & 3.11 & 2.61 & 2.53 & 2.67 & 2.74 & 2.82 \\
\hline
\end{tabular}

*Outstanding =5, Excellent=4, Very Good=3, Fair $=2$, Poor skill=1

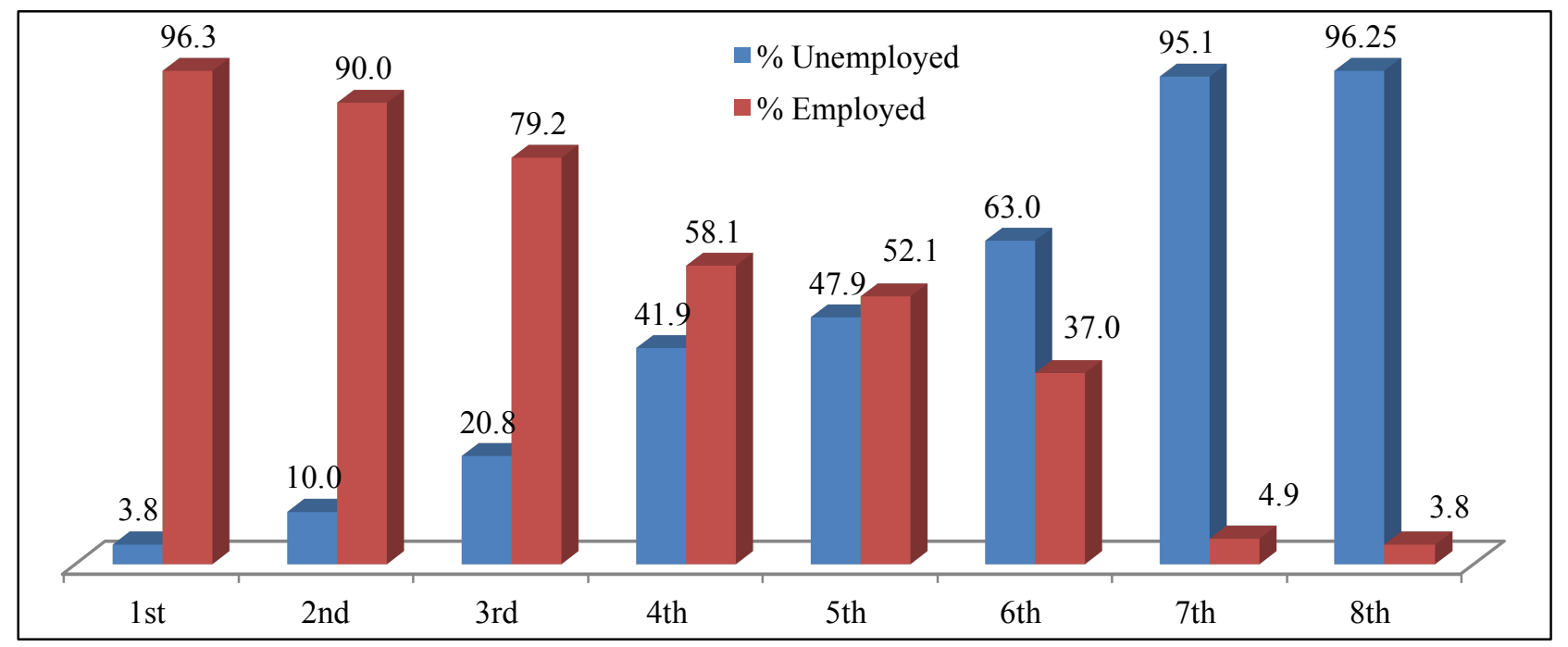

Figure 1 - Distribution of respondents based on employment status 
Close to the total of first batch (96.3\%) graduates are employed, while opposite is obtained in the eight batch. Perhaps, with more years spent without employment after graduation higher experience is gained to compete well in seeking employment.

Results on Figure 2 reveal percent trend of employment status with regard to the eight BS Agriculture batches produced. The employment trend was decreasing steadily with corresponding increase in unemployment from first to fourth batch where it slightly declined before continuing to increase up to the seventh batch.

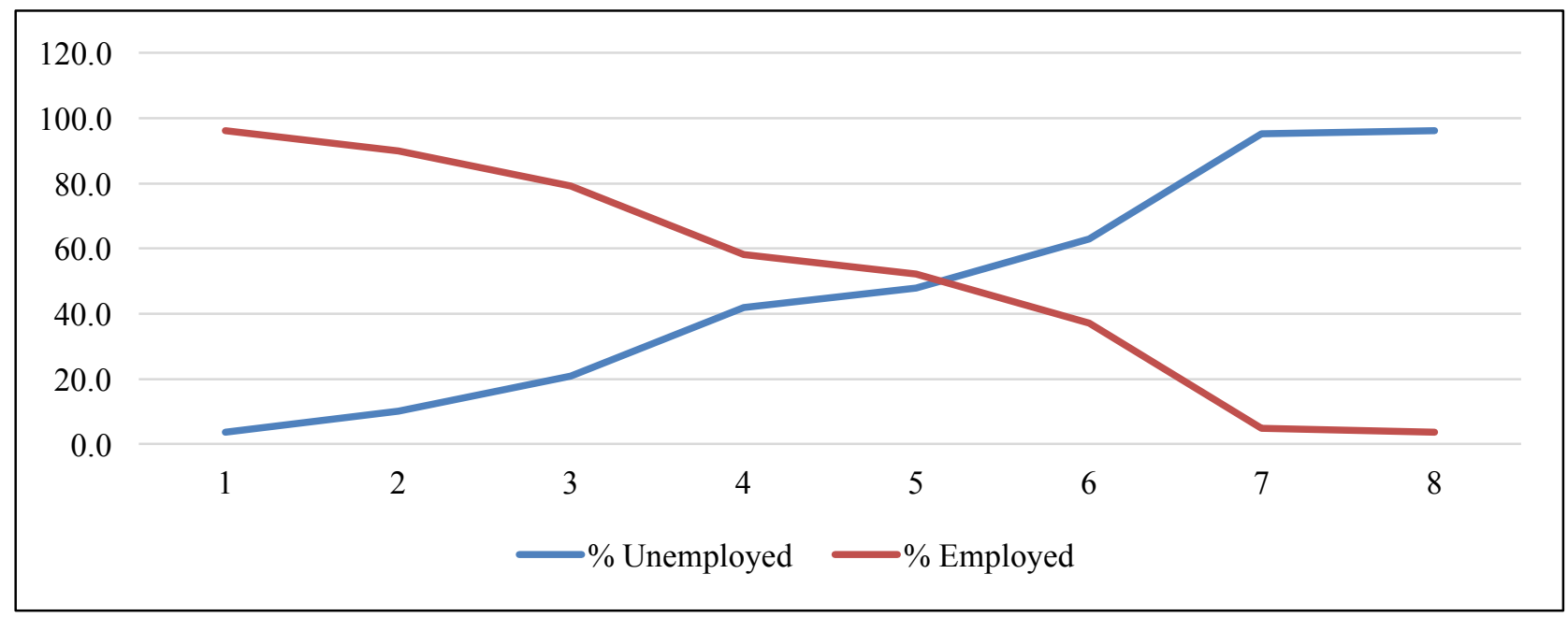

Figure 2. Distribution of graduates based on employment trend

But, from seventh batch to the end employment rate virtually remained the same. Possibly, majority of seventh and eight batch graduates might have enrolled for postgraduate degree or are yet to fully engage in seeking employment.

The batch-wise sector based distribution of BS Agriculture employed graduates is presented in Figure 3. All the employed graduates of seventh batch were employed by public organisations, but most (66.7\%) of the employed eight batch graduates were with private organisations.

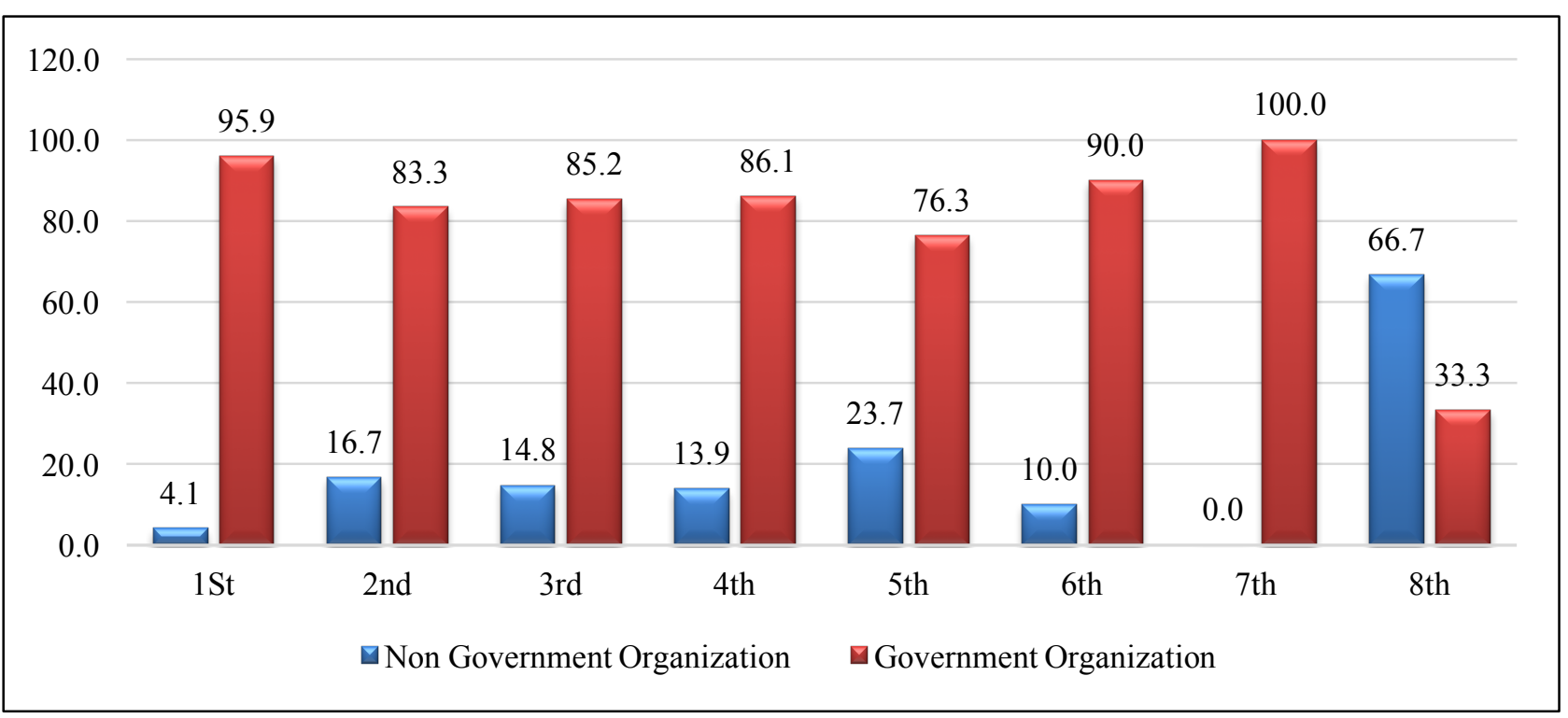

Figure 3 - Distribution of graduates based on sector of employment

Usually, graduates in Bangladesh take up any readily available job that comes their way (most of which is private and casual) while pursuing their dream public employment due to its security and other attached benefits. On the overall, majority of the graduates were employed in the public sector. 
Majority of the graduates were dominantly employed by Research, Bank, Education, Extension and Non-Governmental organisations (Figure 4). A few were with Other cadre, Corporation, Administartion and Business organisations.

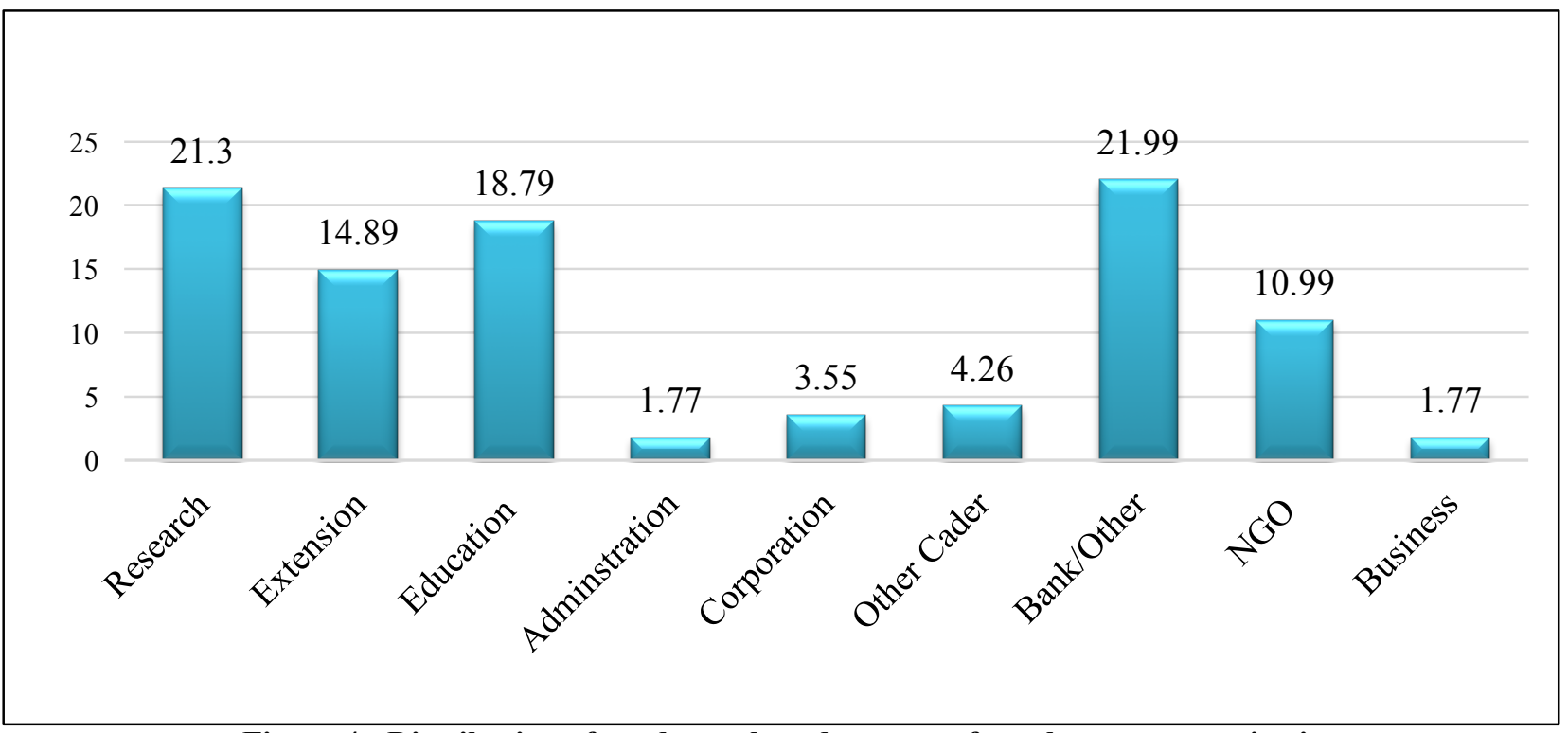

Figure 4 - Distribution of graduates based on type of employment organisation

Large proportion of employed graduates in the said dominated organisations could be a function of relationship of the graduates' specialty with organisations, their quality and/or benefits attached to the working with those type organisations.

Information displayed in Figure 5 reveal that one-fourth $(1 / 4)$ of the total percentage of graduates employed by government are working with research organisations, and nearly equal (24\%) work with bank. Those with education organisation constitute 22 percent, followed by extension (17\%). Graduates employed in other cadre, corporation and administration were few and in the decreasing order of 5, 4 and 3 percent, respectively.

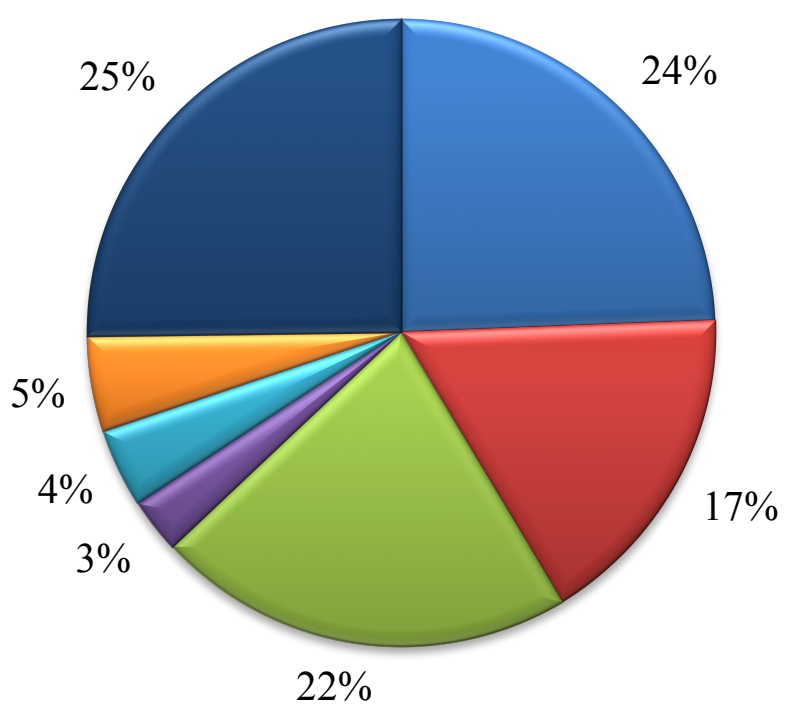

$\square$ Research

Extension

$\square$ Education

$\square$ Administration

$\square$ Corporation

$\square$ Other Cadre

口 Bank/Others

Figure 5 - Distribution of graduates based on governmental organisation employment type

Therefore, majority of BS Agriculture graduates of BSMRAU that are employed by government work with teaching, research and educational organisations. These findings imply that the graduates are working with very relevant organisations that allow application of their BS training. 


\subsection{Level of satisfaction on academic program}

The present study looked at the level of satisfaction based on: i. curriculum design, content and review; ii. teachinglearning and learning assessment; iii. student support; iv. student counselling; v. knowledge achievement; vi. communication skill achievement; vii. interpersonal skills and team work skills achievement; viii. management/leadership skills achievement; and ix. process control.

Curriculum of any program sets limits of its scope, guides what to be learnt and spell out the ultimate outcomes. Out of the five statements relating to design, content and review of curriculum as shown in Table 2, respondents reported most favourably (3.40) that the present BS Agriculture curriculum of BSMRAU has enabled the students to apply their learning outcomes, followed by the curriculum's effectiveness for quality learning (3.15).

Table 2 - Opinion of the respondents on curriculum design, content and review

\begin{tabular}{llll}
\hline Sl\# & Statements & Mean Score & SD \\
\hline 1 & Curriculum was very effective for quality learning & 3.15 & 1.225 \\
2 & Current curriculum was suitable for prospective job/employment opportunity & 2.31 & 1.245 \\
3 & Workload in curriculum was manageable & 2.45 & 1.142 \\
4 & $\begin{array}{l}\text { The course curriculum was satisfactory as per the requirements of the } \\
\text { employers }\end{array}$ & 2.93 & 1.024 \\
5 & Present curriculum has enabled the students to apply learning outcomes & 3.40 & 1.091 \\
\hline
\end{tabular}

At the other end, the respondents reported least favourably (2.31) on the suitability of the current curriculum for prospective job/employment opportunity. This could imply that despite the effectiveness of the current curriculum in providing quality learning and respective application of the learning outcomes, it seems to require regular update to meet up with the trends of job/employment.

Results shown in Table 3 hint that results of eight questions asked to assess the teaching-learning activities and process. Teachers' presence during specified office hours (4.34) was acknowledged highest by the respondents. Majority reported similarly (3.98 and 3.97) on coverage of course contents and maintenance of conducive learning environment by the teachers, respectively.

Table 3 - Opinion of the respondents on teaching-learning and learning assessment

\begin{tabular}{lllc}
\hline SI\# & Statements & Mean Score & SD \\
\hline 1 & Teachers maintained conducive learning environment & 3.97 & 0.898 \\
2 & Teachers were available during the specified office hours & 4.34 & 0.947 \\
3 & Teachers were accessible after class for consultations & 3.97 & 1.025 \\
4 & Overall teaching activities facilitated the learning process & 3.74 & 0.965 \\
5 & The teaching activities promoted students' interaction & 3.69 & 0.995 \\
6 & The assignment and exams covered course content fully & 3.98 & 1.162 \\
7 & Individual potential was explored by this program & 3.21 & 1.321 \\
8 & Evaluation methods were satisfactory & 3.47 & 1.327 \\
\hline
\end{tabular}

Though, all the mean scores were above 3.00 , response concerning exploring individual's potential by the program was least (3.21). Exploring individual's potential is very important in bringing out unknown/hidden talent. Therefore, the present result implies the need to tailor teaching-learning towards eliciting creativity and independence of thought.

Result on Table 4 show information on the university support system. Satisfaction on students' academic progress documentation was highest (3.55), followed by adequacy of faculties to run undergraduate programs effectively (3.33) and maintenance of communication with employers (3.17).

Table 4 - Opinion of the respondents on student support

\begin{tabular}{lllc}
\hline SI\# & Statements & Mean Score & SD \\
\hline 1 & Students' academic progress documentation system was satisfactory & 3.55 & 1.062 \\
2 & The departments had enough faculties to run undergraduate program & 3.33 & 1.316 \\
& effectively & 3.17 & 1.157 \\
3 & University maintained satisfactory communication with the employers & 2.29 & 1.325 \\
4 & University facilitates students for employment and career development & 2.29 \\
\hline
\end{tabular}

However, facilitating students' employment and career development was reported low (2.29). The result implies that career development activities and trainings ought to be part of the university support to students in order to better prepare them as sought for potentials after graduation. 
Although, there exist no available formal structure for student counselling, most of the students are counsel by either their major professors or any teacher a student feels comfortable with. Result on Table 5 shows that satisfaction with academic guidance and counselling system (3.40) was good, so also teaching-learning feedback procedure (3.33).

Table 5 - Opinion of the respondents on student counselling

\begin{tabular}{llll}
\hline Sl\# & Statements & Mean Score & SD \\
\hline 1 & Feedback procedure on teaching-learning was good & 3.33 & 1.205 \\
2 & Academic guidance and counselling system was satisfactory & 3.40 & 1.184 \\
\hline
\end{tabular}

However, it is necessary to formalise the structure given the role of counselling in satisfying psychological, physical and moral needs.

Respondents reported that their enrichment in problem identification and solving capacity (3.36) was better than their satisfaction on acquired knowledge as per professional requirement (2.62).

This information on Table 6 further buttress the least suitability of the present curriculum for prospective job/employment opportunity reported in Table 2.

Table 6 - Opinion of the respondents on knowledge achievement

\begin{tabular}{llll}
\hline Sl\# & Statements & Mean Score & SD \\
\hline 1 & Acquired knowledge was satisfactory as per professional requirement & 2.62 & 1.226 \\
2 & Problem identification and solving capacity was enriched & 3.36 & 1.055 \\
\hline
\end{tabular}

Information on Table 7 show that report writing (3.86), presentation (3.90) and social (3.57) communication skills were all reported by the respondents to have improved more favourably compared to oral communication skill (3.47).

Table 7 - Opinion of the respondents on communication skill achievement

\begin{tabular}{llll}
\hline SI\# & Statements & Mean Score & SD \\
\hline 1 & Oral communication skill developed satisfactorily & 3.47 & 1.096 \\
2 & Report writing skill improved acceptably & 3.86 & 0.805 \\
3 & Presentation skill developed reasonably & 3.90 & 1.103 \\
4 & Social communication skill improved rationally & 3.57 & 0.993 \\
\hline
\end{tabular}

This might not be unconnected to the usual switching over from English to Bengali as teaching medium in most of the cases for better understating of what is being taught.

According to the respondents' opinion presented on Table 8, ability to work with team was highly improved (3.66). Students' ability to cope with challenging situation, improvement in thinking and working skills, ethical values and negotiation skills were more or less obtained to be similar.

Table 8 - Opinion of the respondents on interpersonal skills and team work skill achievement

\begin{tabular}{llll}
\hline Sl\# & Statements & Mean Score & SD \\
\hline 1 & Ability was improved adequately to work with team & 3.66 & 1.222 \\
2 & Students could cope with challenging situation with enhanced ability & 3.47 & 1.273 \\
3 & Independent thinking and working skill improved sufficiently & 3.45 & 1.259 \\
4 & Ethical values improved appreciably & 3.47 & 0.995 \\
5 & Negotiation skill increased reasonably & 3.48 & 0.863 \\
\hline
\end{tabular}

Congenial learning environment, group assigned responsibilities and none disruption of the university activities might be the reasons behind this finding.

Respondents' opinion on management/leadership skills achievement is presented on Table 9. Out of the five statements related to the said opinion, improvement in discipline and punctuality (4.10) had highest positive response. Others were resource and time management skills developed (3.76), improvement in judgement ability (3.53), development of leadership ability (3.52), while improvement in motivation capability had 3.47 . 
Table 9 - Opinion of the respondents on management/leadership skills achievement

\begin{tabular}{llll}
\hline SI\# & Statements & Mean Score & SD \\
\hline 1 & Resource and time management skills developed significantly & 3.76 & 1.159 \\
2 & Judgment ability improved notably & 3.53 & 1.143 \\
3 & Discipline and punctuality improved desirably & 4.10 & 1.054 \\
4 & Leadership ability developed & 3.52 & 1.128 \\
5 & Motivation capability improved optimally & 3.47 & 1.203 \\
\hline
\end{tabular}

This finding implies that the BSMRAU system transforms individuals through acquisition of some relevant management and leadership skills that are essential for running day-to-day issues of life.

Process control directs organisation's return from deviation through checking of errors and taking corrective measures. As indicated on Table 10, result obtained revealed that adherence to academic calendar (4.67) was highly effective. Others that include; quality before quantity, satisfaction in overall students quality control, involvement of all stakeholders in curriculum update and satisfaction in teaching-learning assessment system were in the decreasing order of $3.84,3.78,3.21$ and 3.17 , respectively.

Table 10 - Opinion of the respondents on process control

\begin{tabular}{llll}
\hline SI\# & Statements & Mean Score & SD \\
\hline 1 & Assessment system of teaching-learning was satisfactory & 3.17 & 1.230 \\
2 & Academic calendar was strictly followed & 4.67 & 0.825 \\
3 & Overall student quality control of BSMRAU was satisfactory & 3.78 & 1.109 \\
4 & Curriculum is updated involving all stakeholders & 3.21 & 1.210 \\
5 & Quality was considered first, then quantity & 3.84 & 1.121 \\
\hline
\end{tabular}

On average scale, this finding implies strong BS Agriculture program in terms process control, though, satisfaction in teaching-learning assessment system and involvement of all stakeholders in curriculum update were relatively reported low.

Results presented in Table 11 reveal that majority reported that the strong point of BS Agriculture is adherence to academic calendar (71.92\%). This can however be a function of politics free environment $(22.80 \%)$ and influenced maintenance of class schedule $(14.03 \%)$. A considerable number also reported good teacher-student relationship (15.78\%), effective curriculum for quality learning $(12.28 \%)$ and good laboratory facilities $(10.52 \%)$. Low reported strong points include maintenance of 80 percent attendance, skilled teachers, and practical oriented teaching-learning and very good evaluation system $(1.75 \%$ each $)$.

Table 11 - Opinion on BS (Agriculture) strong points

\begin{tabular}{llcc}
\hline SI\# & Statements & Frequency & Percent \\
\hline 1 & Adherence to academic calendar & 41 & 71.92 \\
2 & Good teacher-student relationship & 9 & 15.78 \\
3 & Maintenance of class schedule & 8 & 14.03 \\
4 & Politics free environment & 13 & 22.80 \\
5 & Good laboratory facilities & 6 & 10.52 \\
6 & Orderliness/Discipline & 5 & 8.77 \\
7 & Attractive learning environment & 4 & 7.01 \\
8 & Course credit system & 4 & 7.01 \\
9 & Emphasis on quality over quantity & 4 & 7.01 \\
10 & Good accommodation facility & 3 & 5.26 \\
11 & Effective curriculum for quality learning & 7 & 12.28 \\
12 & Maintenance of 80\% attendance & 1 & 1.75 \\
13 & Skilled teachers & 1 & 1.75 \\
14 & Practical oriented teaching-learning & 1 & 1.75 \\
15 & Very good evaluation system & 1 & 1.75 \\
\hline
\end{tabular}

Adherence to academic calendar highly reported is a unique feature that differentiate BSMRAU from other universities, and which expressed the graduates' satisfaction in the order of conduct of academic affairs of the university. 
The weak points of BS Agriculture are presented on Table 12. Out of the twenty two raised points, majority reported less of extracurricular activities $(39.00 \%)$, followed by no career based learning $(26.31 \%)$, poor transport facility to Dhaka and staff and employee don't respect student $(19.30 \%$ each). Least reported weak points include excess academic load and short duration of courses $(1.75 \%$ each).

Table 12 - Opinion on BS (Agriculture) weak points

\begin{tabular}{llcc}
\hline SI\# & Statements & Frequency & Percent \\
\hline 1 & Tight final exam schedule & 5 & 8.77 \\
2 & Shortage of some important courses & 3 & 5.26 \\
3 & Less response to students' suggestion & 3 & 5.26 \\
4 & Shortage of some laboratory equipment & 2 & 3.50 \\
5 & Lack of Teacher-Student centre & 3 & 5.26 \\
6 & Too much repeated courses & 9 & 15.78 \\
7 & Less extracurricular activities & 22 & 39.00 \\
8 & No career based learning & 15 & 26.31 \\
9 & Shortage of books in library & 5 & 8.77 \\
10 & Less scope for extra study & 5 & 8.77 \\
11 & Biasness of some teachers' & 6 & 10.52 \\
12 & Costly enrolment and admission fee & 6 & 10.52 \\
13 & Individual potentiality is not explored & 9 & 15.78 \\
14 & Less field visit & 6 & 10.52 \\
15 & Absence of research component & 2 & 3.50 \\
16 & Poor transport facility to Dhaka & 11 & 19.30 \\
17 & Excessive academic load & 1 & 1.75 \\
18 & No student association & 2 & 3.50 \\
19 & Staff and employee don't respect student & 11 & 19.30 \\
20 & Short duration of courses & 1 & 1.75 \\
21 & Inadequate presentation & 2 & 3.50 \\
\hline
\end{tabular}

Highest response to less extracurricular activities has reflected the reality of the existing situation as the university is on the effort to put in place the required extracurricular structures and most of the BS Agriculture students were teenagers on transition to adulthood, thus attracted to entertainment and recreational activities.

A number of suggestions made for improvement of BS Agriculture program are presented on Table 13. Practical should be done in a practical way and provision of some laboratory equipment were equally reported highest $(26.08 \%)$. Improvement of transport system, more student presentation and international collaboration were also equally reported $(8.70 \%)$. Likewise, inclusion of English language course, update of course content, more field trip, inclusion of research work and career related courses were reported equally (4.34\%).

Table 13 - Suggestion for improvement of BS (Agriculture) program

\begin{tabular}{llcc}
\hline SI\# & Statements & Frequency & Percent \\
\hline 1 & Inclusion of English language course & 1 & 4.34 \\
2 & Practical should be done in a practical way & 6 & 26.08 \\
3 & Provision of some laboratory facilities & 6 & 26.08 \\
4 & Improvement of transport system & 2 & 8.70 \\
5 & Updated of course content & 1 & 4.34 \\
6 & More field trip & 1 & 4.34 \\
7 & More student presentation & 2 & 8.70 \\
8 & Inclusion of research work & 1 & 4.34 \\
9 & International collaboration & 2 & 8.70 \\
10 & Career related courses & 1 & 4.34 \\
\hline
\end{tabular}


This finding highlights the needs of graduates and what could be done to better the BS Agriculture program. In addition, it shows areas of inadequate satisfaction by the graduates.

\section{Qualitative Findings}

To obtain the qualitative data, three different focus group discussions were conducted with representatives from each stratum. The focus group discussions involved 5 respondents from alumni and service providers, and 10 from MS degree students who completed their BS Agriculture from BSMRAU. In each session, the discussion lasted for 60 minutes.

Findings from the three different focus group discussions also revealed a moderate degree of appreciation of the generic skills especially from agricultural extension and rural development courses. This was due to the direct application of the learning outcomes in day-to-day life in the work place and larger society. However, enhancement of soft and entrepreneurship skills were reported to be missing in the present BSMRAU BS Agriculture curriculum. On a positive note, the participants reported that, from its beginning BSMRAU was very strong in complying with its academic calendar along with maintaining strict rules and regulation in all academic affairs. Teachers also used to maintain friendly relationship with the students. The university has good accommodation system devoid of any student political interruptions that attracts prospective students.

\section{Conclusions}

Based on the findings of the study and their relevant discussions the following have been drawn as conclusions:

$\checkmark$ Most of the BS Agriculture graduates acquired generic skills related to communication and ICT, interpersonal, teamwork and leadership skills, and self-management and personal development skills from Agricultural Extension and Rural Development offered courses. In this regard, this study suggests collaborative learning activities in all courses and encouraging such outside classroom, establishing links with real life situations, and problem based learning for practical works.

$\checkmark$ The employability of BS Agriculture graduates was high in the early years after graduation due to the fast absorption of fresh graduates living a few behind to constitute small percentage with increasing number of years after graduation. Governmental organisations that include research, extension, education and bank absorbed majority of the graduates.

$\checkmark$ Higher level of satisfaction was expressed in teaching-learning, communications skills and process control, while curriculum update and knowledge achievement were low satisfied. Major perceived strength was adherence to academic calendar while less extracurricular activities was the major weakness. Carrying out practical in a practical way/provision of some important laboratory equipment was suggested for improvement.

\section{Acknowledgement}

The authors recognize the research wing of Bangabandhu Sheikh Mujibur Rahman Agricultural University for both material and non-material support to conduct the research work, especially the RMC project funding.

\section{Reference}

Burkart, K. (2013). 6 indicators of employee performance. Retrieved on May, 26: http://www.usbankconnect.com/article/6-indicators-employee-performance.

Kirkpatrick, D. L. \& Kirkpatrick, J. D. (2006). Evaluating training programs: the four levels (3rd Edition). BerrettKoehler Publishers, Oakland, USA, pp. 392.

Miles, M. B. \& Huberman, A. M. (1994). Qualitative data analysis: an expanded sourcebook (2nd Ed.). SAGE Publications, Inc., Thousand Oaks, California, USA, pp. 10-11

Saunders, V. \& Zuzel, K. (2010). Evaluating employability skills: Employer and student perceptions. Bioscience Education, 15(1), 1-15.

Smith, C., \& Bath, D. (2006). The Role of the Learning Community in the Development of Discipline Knowledge and Generic Graduate Outcomes. Higher Education, 51(2): 259-286.

University Grants Commission of Bangladesh. (2016). Self-Assessment Manual (2nd revised edition). Dhaka, Bangladesh: Higher Education Quality Enhancement Project (HEQEP). Retrieved on May, 23 www.heqep-ugc.gov.bd

Yorke, M. (2006). Employability in higher education: what it is - what it is not. Learning and Employability Series 1. York: The Higher Education Academy. Retrieved on June, http://www.heacademy.ac.uk/assets/documents/tla/employability/id116_employability_in_higher_education_336.pdf 